prevalence and risk factors among Sri Lankan rubber tappers, and identifies possible interventions to improve worker safety.

Methods A mixed-methods questionnaire was administered to 300 Sri Lankan rubber tappers between September and November 2014. Information was obtained on demographics, injuries, work environment, behavioural characteristics, and depression. Open ended questions were included to allow participants to provide additional comments.

Results 300 rubber tappers reported a total of 594 injuries in the previous 12 months, which resulted in 1080 days of work missed. Knife cuts $(n=182)$ and skin irritation $(n=176)$ were the most common injuries. Snake bites were less common $(n=26)$ but the most severe injury type, resulting in an average of 9.8 (SD = 10.7) days of work missed per injury. Predictors of injuries varied by injury type; they were gender (falls, snake bites), working an additional job (knife cuts), tapping with a two handed approach (skin irritation), and depression (skin irritation, falls). No workers reported wearing personal protective equipment. Qualitative findings suggest that four interventions could address most injuries: 1) use of safety glasses for upper tapping, 2) landscaping of rubber lands, 3) provision of eyeglasses for the vision impaired, and 4) use of equipment to reduce manual transport of latex.

Conclusions Sri Lankan rubber tappers experience a heavy burden of work-related injuries and have limited safety equipment. The four interventions identified by this research could help reduce the risk of occupational injury to rubber tappers.

\section{SAFE AND EFFECTIVE TRAINING FOR WORKING WITH DIFFICULT TREES USING A CHAIN SAW}

Marko Hassinen. Emergency Services College, Finland

\subsection{6/injuryprev-2016-042156.581}

Background With the change in climate, storms are increasing in many parts of the world. One of the most challenging tasks in terms on occupational safety in these situations is removing storm fallen trees that have tensions. This work has more risks than usual and is also rather difficult to train. At the same time, it is often done by rescue workers or power company employees using a chain saw.

Methods We surveyed the types of situations in which chain saw work leads to injuries and how often these situations are affected by the trees been damaged or having abnormal tensions. Very often such conditions are met by Fire $\&$ Rescue crews clearing roads and other areas from trees that a storm has fallen. A number of workshops were arranged to collect the knowledge from a group of experienced experts.

Results Based on the workshops a two part training program was developed. To make the training effective, two simulators were designed. The other one is based on a commercial product, while the other one was designed and drawn by engineers in close cooperation with the research team. In the first simulator, cutting trees under tension is trained in a safe environment. The other simulator is used in further training and can be used to train removing trees fallen on power lines, houses, cars and other similar places.

Conclusions Fire and Rescue services, as well as others can improve their level of occupational safety in removing difficult trees. Using a chain saw to remove a tree with abnormal tensions requires both knowledge and adequate practice. This can be achieved through training and the simulators make training both safe and productive.

\section{EVALUATING THE IMPACT OF WORKSAFE NEW ZEALAND ON THE CANTERBURY REBUILD}

Rosalind Houghton, Will Bell. WorkSafe New Zealand

10.1136/injuryprev-2016-042156.582

Background The Canterbury region in New Zealand is currently in the middle of a major rebuild following two large and thousands of smaller earthquakes in 2010 and 2011. The construction sector has experienced unprecedented demand, which was expected to impact on the health and safety practices of the sector. WorkSafe New Zealand partnered with the sector to establish a safety charter for good practice, as well as establishing a dedicated inspectorate resource for the initial stages of the rebuild.

Methods The evaluation utilised a mixed method approach, including injury data analysis, modelling, surveying, interviews and documentation review to understand the impact of WorkSafe's involvement.

Results Results are still being analysed, but will be available at the time of the presentation.

Conclusions The Canterbury Rebuild provided a unique opportunity for the regulator and construction sector to work in partnership in a time of significant demand, with the goal of preventing severe injury and fatalities. The use of the charter, and sector-led work, is being examined as a potential blueprint for other sectors of priority in New Zealand.

\section{HAND INJURIES IN THE UNITED ARAB EMIRATES}

${ }^{1}$ Michal Grivna, ${ }^{2}$ Hani $O$ Eid, ${ }^{2}$ Fikri M Abu-Zidan. ${ }^{1}$ Institute of Public Health, College of Medicine and Health Sciences, UAE University, Al Ain, UAE; ${ }^{2}$ Department of Surgery, College of Medicine and Health Sciences, UAE University, Al Ain, UAE

\subsection{6/injuryprev-2016-042156.583}

Background We aimed was to study epidemiology, risk factors and outcome of hospitalised patients with hand injuries in order to give recommendations for prevention.

Methods We studied all trauma patients having hand injuries admitted to $\mathrm{Al}$ Ain Hospital for more than 24 hours, or died after arrival to the hospital during 3 years. Demography, location and time of injury, other injured regions, severity of injury, hospital and ICU stay, and outcome were analysed.

Results 296 patients having a mean age of 30.5 years were studied. The annual incidence of hospitalisation was $15.4 / 100$ 000 person per year. $91.9 \%$ were males and $62.5 \%$ from the Indian subcontinent. The most common location for injury was work (53.4\%), followed by road (24.7\%) and home (13.2\%). Injury from road traffic crash was the most common mechanism (26\%), followed by machinery (25.7\%) and heavy objects $(14.9 \%)$. Patients injured at home were younger $(\mathrm{p}<0.0001)$ and had more females ( $\mathrm{p}<0.0001)$.

Conclusions Males from the Indian subcontinet are at a higher risk of having hand injuries especially at work, while UAE nationals by traffic or at home. Safety education and programs, use of personal protective equipment including gloves, and proper enforcement of the safety guidelines could reduce hospitalizations and disability of hand injuries. 